\title{
Analysis of the Performance of an All-optical Network Using Arrayed Waveguide and Fiber Bragg Grating Demultiplexers
}

\section{Análise do Desempenho de uma Rede Totalmente Óptica Usando Matriz de Guia de Onda e Demltiplexadores com Grade de Bragg em Fibra}

\author{
Lelis Araujo de Oliveira ${ }^{1,2 *}$, Fabio Barros de Sousa ${ }^{1}$, Jackson Moreira Oliveria ${ }^{1}$, Hudson \\ Afonso Batista da Silva ${ }^{1,2}$, Jorge Everaldo de Oliveira ${ }^{1}$, Fabrício Pinho da Luz ${ }^{1}$, Fabio Souza de \\ Araújo $^{1}$, Alan dos Reis Silva ${ }^{1}$, Marcos Benedito Caldas Costa ${ }^{1,3}$
}

\begin{abstract}
This work aims to discuss a study of numerical simulations of the performance of arrayed waveguide grating (AWG) and fiber Bragg grating (FBG) demultiplexers in a fiber optical network in a special class of fiber denominated fiber of photonic crystal (PCF) considering the dispersive and non-linear effects. The proposed method is based on numerical simulations in a wavelength division multiplexing (WDM) network configuration in PCF. For the simulation and analysis, the commercial OptiGrating software was used, a versatile numerical tool used to model integrated devices that incorporate FBG and OptiSystem software to simulate fiber propagation with non-linear and dispersive characteristics. The analysis of the performance of the systems was done through a comparison between the values obtained in terms of Bit Error Rate (BER) and Quality Factor (Q Factor) in a dense WDM system with spacing between $50 \mathrm{GHz}$ channels, and $12 \mathrm{Gbit} / \mathrm{s}$ transmission rate. The results show that the FBG demultiplexer in terms of the BER and the Q factor for the PCF was the one that obtained the best performance, when compared the FBG demultiplexer with SMF and the AWG demultiplexer obtained excellent results for both fibers.
\end{abstract}

Palavras-chave: Arrayed Waveguide Grating; Fiber Bragg Grating; Wavelength Division Multiplexing.

\section{RESUMO}

Este trabalho tem como objetivo discutir um estudo de simulações numéricas do desempenho de demultiplexadores grades de guias de onda (AWG) e de fibra com grade de Bragg (FBG) em uma rede de fibra óptica em uma classe especial de fibra denominada fibra de cristal fotônico (PCF) considerando as características dispersivas e os efeitos não lineares. O método proposto é baseado em simulações numéricas em uma configuração de rede de multiplexação por divisão de comprimento de onda (WDM) em PCF. Para a simulação e análise, foi utilizado o software comercial OptiGrating, uma ferramenta numérica versátil utilizada para modelar dispositivos integrados que incorporam FBG e o software OptiSystem para simular a propagação em fibras com características não lineares e dispersivas. A análise do desempenho dos sistemas foi feita através da comparação entre os valores obtidos em termos da taxa de erro de bit (BER) e do fator de qualidade (Q-Factor) em um sistema WDM denso com espaçamento entre canais de $50 \mathrm{GHz}$ e taxa de transmissão de $12 \mathrm{Gbit} / \mathrm{s}$. Os resultados mostram que o desmultiplexador FBG em termos da BER e do fator Q para a PCF foi o que obteve melhor desempenho, quando comparado o desmultiplexador FBG com SMF e o desmultiplexador AWG obteve excelentes resultados para ambas as fibras.

\footnotetext{
${ }^{1}$ Universidade Federal do Pará.

${ }^{2}$ Instituto Federal de Educação, Ciência e Tecnologia do Pará.

${ }^{3}$ Faculdade de Engenharia de Materiais da Universidade Federal do Pará - Ananindeua.

*E-mail: lelis.oliveira@ifpa.edu.br
} 
Keywords: grades de guias de onda; fibra com grade de Bragg; multiplexação por divisão de comprimento de onda.

\section{INTRODUTION}

The widespread use of the Internet, digital communications and real-time processing technologies generates a constant demand for an increase in transmission capacity and in the transmission range of fiber optic links. It turns out that the increase in the transmission range in optical fibers produces some unwanted effects, since optical fibers are systems that naturally present various types of dispersion and associated nonlinear effects when the power of light input into the fiber is increased. To eliminate these effects, different methods of optical fiber design are used or there is also production of fibers with dispersion. One of these fibers is the PCF, which consists of optical fibers that have a central region and a periodic shell composed of air holes of micrometric size allowing engineers to easily modify the dispersion properties.

The PCFs can be an option for the growing demand for new telecommunications services and the need to transmit a large volume of data in WDM optical systems, since dispersion can be controlled by modifying the diameter, number, shape and inclination of the air holes in the fiber shell (CONNOLLY et al., 2006). The WDM systems encompass the technology of multiplexing and demultiplexing a huge variety of channels on just one fiber, and this becomes a major challenge for researchers. The WDM system presents classifications that take into account the frequency spacing of the channels, which is found in the 50-100 GHz spacing is known as Dense Wavelength Division Multiplexing (DWDM), which was used in this work, and has the purpose of transmitting multi wavelengths in very low frequency spacing in the fiber (DONG et al., 2012; YADAV et al., 2015).

These optimizations of WDM demultiplexers have been widely studied, as in who performed an analysis of the performance of AWG demultiplexers and a demultiplexer based on FBGs on a passive WDM, dense, ultra-dense optical network with a transmission rate of $10 \mathrm{Gbit} / \mathrm{s}$. In an experimental performance analysis was carried out without dispersion compensation or optical timing of multiplexers by frequency division using an FBG or AWG on the receiver. In a study was carried out to evaluate the impact of demultiplexers based on the FBG filter on the performance of the DWDM system for 
optical access networks, where FBG filters (ie uniform FBG, Gaussian apodized grating, FBG with chirp) are characterized to explain their behavior in the optical link. In a study was carried out to measure the impact of the insertion of demultiplexers based on the FBG filter in the DWDM transmission system, where the impact of demultiplexers in the 10 Gbit/s DWDM system is investigated for the encoding formats NRZ-OOK (YADAV, 2015; BENAMEUR, 2014; HOXHA, 2015).

Thus, this work aims to discuss a study of numerical simulations using the Optisystem and Optigrating software for the performance of AWG and FBG demultiplexers on a fully optical link in a Standard Single Mode Fiber (SMF) and a PCF considering the dispersive and nonlinear effects. The demultiplexed signal underwent simulations, the first by the standard single-mode fiber for the demultiplexers AWG and FBG and the second by a Highly Nonlinear Photonic Crystal Fiber (HNL-PCF) in the same way as the standard fiber. Our work investigates the performance of the AWG and FBG demultiplexers, referred to here as Demux-awg and Demux-fbg, respectively. In sections 2 and 3 we present a theoretical and structural analysis of demultiplexers, while in section 4 we analyze and discuss the results obtained. In section 5 we present the conclusion, as well as acknowledgments and references.

\section{THEORETICAL ANALYSIS}

\subsection{Demultiplexers AWG and FBG}

The AWG is a generalization of the Modelator Mach-Zehnder (MZM), which associates two $N \times M$ star couplers through several $M$, waveguides, in such a way that the wavelengths between two consecutive guides are constant. The WDM signal at the entrance is coupled in an array of planar waveguides, thus, each waveguide suffers a different lag due to the different lengths of the guides (AGRAWAL, 2012), resulting in a phase difference between two adjacent paths in the arrangement of waveguide, figure $1 \mathrm{a}$.

The working principle becomes clear if we consider it as a set of waveguides, figure $1 b$. We write the difference in the propagation of waves in neighboring channels on the axis of the coupling plate considering that the difference between the lengths of the adjacent $\Delta L$ waveguides, forming this arrangement, be the same, thus, this difference $\Delta \phi$ is equal to the maximum light intensity for an integer number of waves (TAKAHASHI, 1990; COSTA, 2013): 


$$
\Delta \phi=\Delta L n_{c}+n \sin \phi d=m \lambda,
$$

where, $m$ is an integer, called diffraction order, $\lambda$ is the wavelength of light in a vacuum, $\Delta L$ is the difference in length of the adjacent waveguides, $d$ is the period of its location, $n_{c}$ is the refractive index of the waveguide mode and $n$ is the refractive index of the area where light propagation occurs.

Figure 1 - (a) AWG with an increased optical path difference between diffractive elements and (b) AWG principle.

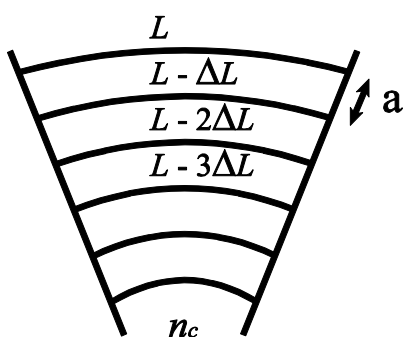

$n_{c}$

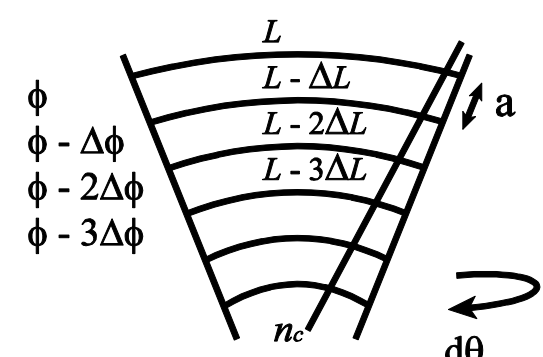

(a)

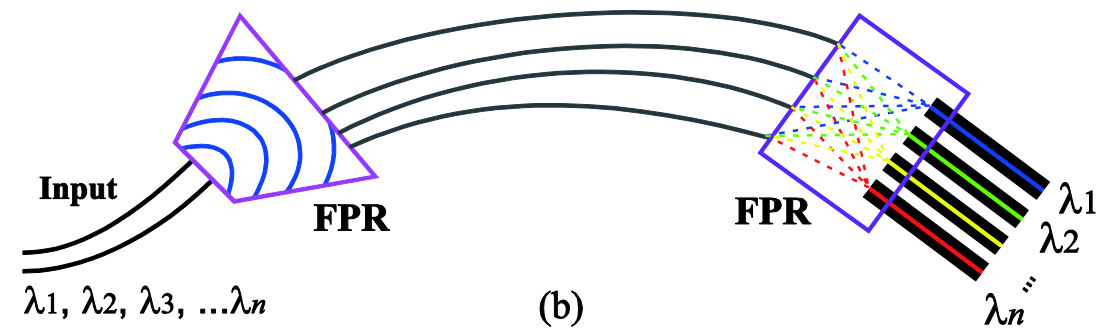

Fonte: Oliveira et al. (2022).

If constructive interference occurs, the maximum transmission will be given by equation 2 , when $\Delta \varphi=2 \pi m$ on the axis of the coupling plate, figure $1 \mathrm{~b}$ :

$$
\lambda=n_{c} \Delta L / m \text {. }
$$

Bragg's condition happens when there is conservation of energy and momentum. The conservation of energy requires that the frequencies incident and reflected radiation be the same. The conservation of momentum requires that the incident wave vector, $\kappa_{i}$ more the grating wave vector $\mathrm{K}$, be the same equal to the scattering wave vector $\kappa_{f}$, this is:

$$
\kappa_{i}+\mathrm{K}=\kappa_{f},
$$


where the wave vector of grating $\mathrm{K}$, has direction normal to the plane of the grating, whose intensity is $2 \pi / \Lambda$ (being $\Lambda$ the modulating period of the grating refractive index). The diffracted wave vector has the same intensity, but its direction is opposite to the incident wave vector. Thus, the conservation condition of the first order moment of Bragg for a wavelength is given by (DOCKNEY et al., 1996):

$$
\lambda_{\text {Bragg }}=2 n_{\text {eff }} \Lambda
$$

where $\lambda_{\text {Bragg }}$ is the wavelength of the input light that will be reflected back and $n_{\text {eff }}$ is the effective refractive index of the fiber core at its wavelength.

Figure 2 - Schematic of a uniform Bragg network with constant amplitude index and modulation period. Also shown are the vectors of incident, diffracted and grating waves that need to be combined for conservation of momentum.

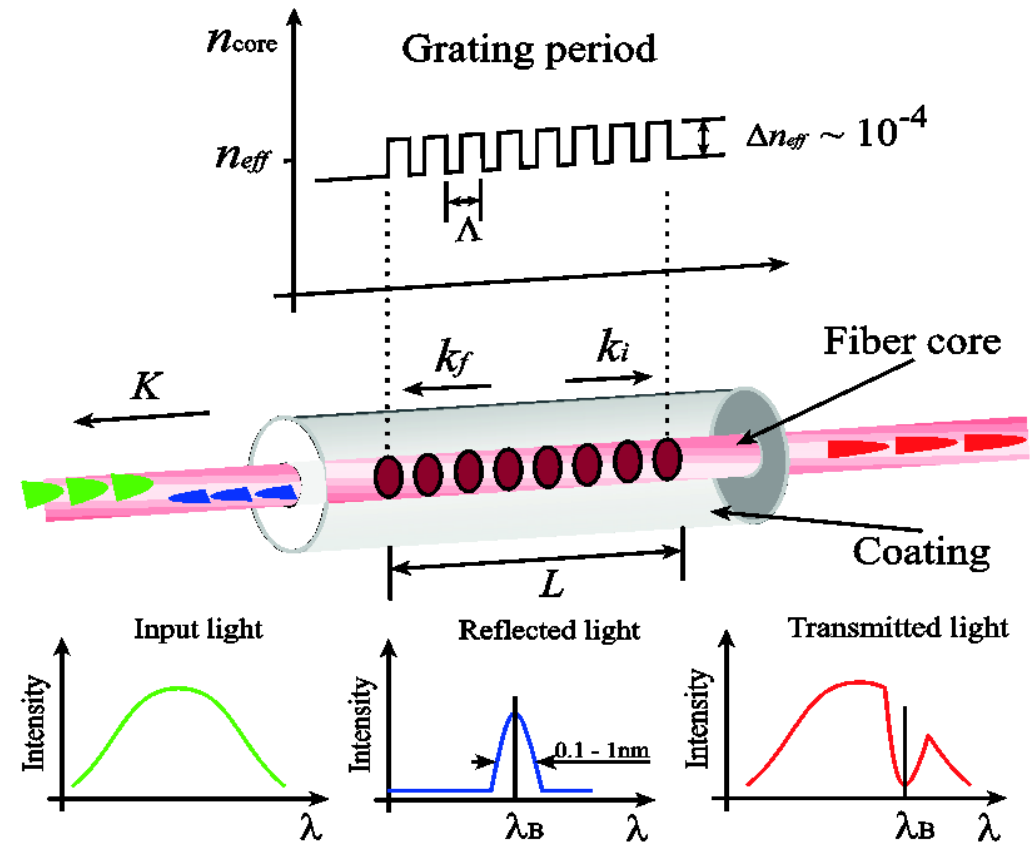

Fonte: Oliveira et al. (2022).

The FBG is a simple filter distributed on an optical fiber whose function is to select certain wavelengths of light and transmit the others. It performs reflection operations with high efficiency and low losses (about $0.3 \mathrm{~dB}$ ) (HILL et al., 1978; DOCKNEY et al., 1996). In addition, it acts as a chromatic dispersion compensator, where maximum reflectivity occurs when the Bragg condition is satisfied, figure 2. 


\section{SIMULATION SETUP}

The figure 3 shows the simulation project proposed in this work, which was developed using the OptiSystem 17.0, where the parameters of the FBG were imported from OptiGrating 4.2 in .txt files. In the simulations, an arrangement was used with 16 Continuous Wave - CW laser transmitters each with frequencies ranging from 193.10 $\mathrm{THz}$ to $193.85 \mathrm{THz}$, where the channels were spaced at $50 \mathrm{GHz}$. The pumping power in each transmitter was $0 \mathrm{dBm}$ and the link has a transmission rate of $12 \mathrm{Gbit} / \mathrm{s}$.

The transmission section has 16 subsystems, named Trm-1 to Trm-16. Each transmitter has the following configuration: Pseudo Random Bit Sequence (PRBS), responsible for producing the bits to be encoded by the Pulse No Return to Zero (NRZ); Mach-Zehnder (MZM) Modulator, which modulates wavelengths, with a symmetrical factor of -1 and an extinction rate of $30 \mathrm{~dB}$; Pulse Generator (NRZ), which generates No Return to Zero (NRZ) pulses and Laser (CW Laser), power source in simulations of 0 $\mathrm{dBm}$ at a frequency of $193.10 \mathrm{THz}$ (DE SOUSA et al., 2019).

In the demultiplexing section, the signal is multiplexed in the WDM Mux, which has an initial frequency of $193.10 \mathrm{THz}$, a bandwidth of $20 \mathrm{GHz}$, an insertion loss of 0 and a Bessel filter of order 2. The multiplexed signals are launched on the fiber, which in a first simulation was used the demultiplexer AWG, referred to here as Demux-awg for the standard $50 \mathrm{~km}$ length SMF fiber and the $0.7 \mathrm{~km}$ length HNL-PCF fiber, figure 3 . In a second simulation, the FBG demultiplexer was used, referred to here as Demux-fbg for the $50 \mathrm{~km}$ length SMF standard fiber and the $0.7 \mathrm{~km}$ length HNL-PCF fiber, figure 3 . The SMF and HNL-PCF parameters are listed in table 1.

The reason for choosing HNL-PCF was due to its non-linearity coefficient, which in most cases is higher than that of SMF silica, as well as the fact that this type of fiber reduces the average power capacity of the pulses of control and the group speed mismatch problem. In addition, very short lengths of HNL-PCF are required to achieve a sufficient number of nonlinear effects and also improve system integration (YADAV et al., 2015; KEISER, 2008; SOUSA et al., 2018).

We chose the Gaussian apodization function with a Gaussian parameter of 0.5, because we can effectively minimize the reflectivity of the side lobes or eliminate them, in addition to offering a better spectral response, which allows to increase the isolation of adjacent channels, which is very useful in design of multiplexers, in our case, the lobes 
were minimized by the shape of the Gaussian function and the choice of the Gaussian parameter. Another important parameter is the chirp period, which was selected for the linear mode of $0.28 \mathrm{~nm}$ linear parameter providing a grating with dispersion compensation. After the signals are transmitted by any of the Demux, they arrive at the reception section, where any channel has the following components: a photodetector positive-intrisic-negative (PD PIN); 4th order low-pass filter (LPBF); regenerator 3R (3R RG) and BER Analyzer.

Figure 3 - Scheme of the simulation project.

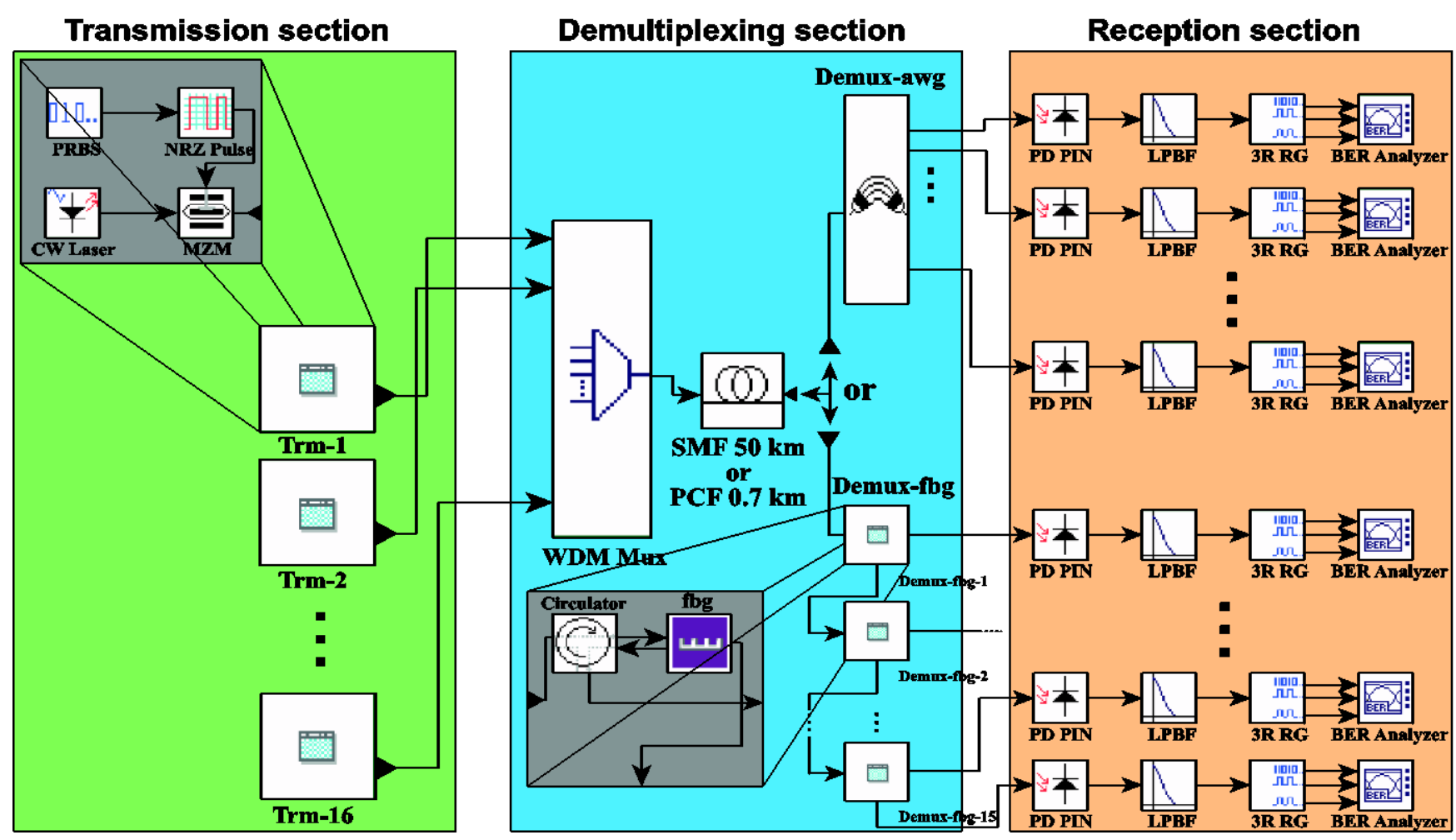

Fonte: Oliveira et al. (2022).

Table 1 - Transmission section.

\begin{tabular}{|c|c|c|}
\hline Parameters of optical fibers & SMF & HNL-PCF \\
\hline Reference wavelength & $1550 \mathrm{~nm}$ & $1550 \mathrm{~nm}$ \\
\hline Attenuation & $0.2 \mathrm{~dB} / \mathrm{km}$ & $5 \mathrm{~dB} / \mathrm{km}$ \\
\hline Dispersion & $16.75 \mathrm{ps} / \mathrm{nm} / \mathrm{km}$ & $-1216 \mathrm{ps} / \mathrm{nm} / \mathrm{km}$ \\
\hline Dispersion slope & $0.075 \mathrm{ps} / \mathrm{nm}^{2} / \mathrm{km}$ & $-0.26 \mathrm{ps} / \mathrm{nm}^{2} / \mathrm{km}$ \\
\hline Effective area & $80 \mu \mathrm{m}^{2}$ & $1.81 \mu \mathrm{m}^{2}$ \\
\hline Refractive index & $2.6 \times 10^{-20} \mu \mathrm{m}^{2} / \mathrm{W}$ & $2.6 \times 10^{-20} \mu \mathrm{m}^{2} / \mathrm{W}$ \\
\hline Nonlinearity Coefficient & $1.3 \mathrm{~W}^{-1} \mathrm{~km}^{-1}$ & $1.3 \mathrm{~W}^{-1} \mathrm{~km}^{-1}$ \\
\hline Differential Group Delay & $0.2 \mathrm{ps} / \mathrm{km}$ for the $50 \mathrm{~km} \mathrm{SMF}$ & $0.2 \mathrm{ps} / \mathrm{km}$ for the $0.7 \mathrm{~km}$ HNL-PCF \\
\hline
\end{tabular}

Fonte: Oliveira et al. (2022). 


\section{RESULTS AND DISCUSSION}

The optical spectra along the link are shown in figure 6 . The figure $6 a$ shows the optical power spectrum of the 16 fiber input channels, the input power was set to $0 \mathrm{dBm}$. Figure $6 \mathrm{~b}$ shows the optical spectrum of the same channels after leaving the SMF fiber, and figure $6 \mathrm{c}$ shows the optical spectrum of the 16 channels, but now after leaving the HNL-PCF.

It is observed that the channels suffered an attenuation of $-14 \mathrm{dBm}$ and the production of approximately 14 lateral bands, known as FWM products, with powers ranging from -65 to $-75 \mathrm{dBm}$ generated from the signal propagated in the SMF fiber and around 16 lateral bands, with powers ranging from -57 to $-67 \mathrm{dBm}$ for HNL-PCF (KEISER, 2008; DE SOUSA et al., 2019; DE SOUSA et al., 2020; SABINO et al., 2017). The changes in the spectra represented in figures $6 \mathrm{~b}$ and $6 \mathrm{c}$ are due to the FWM, not due to the increase in the pumping power in the fibers, since they are the same for both and the influence of the FWM is reduced by reducing the total optical power in the fiber, but due to the change in the parameters of the dispersion coefficient and effective area of the fiber, as as seen in and there is a change in the side bands due to the FWM when these parameters undergo some variation. In addition, the degradation imposed by the FWM effect increases with the decrease in spacing between channels, since, in this work, as in, the systems used work with channel spacing very close, that is, with $50 \mathrm{GHz}$, and this reduces the group speed mismatch between channels (BHUSARI SHRADDHA, 2016).

The table 2 and table 3 below show the gain values in $\mathrm{dB}, Q$ factor, BER, input power and output power in $\mathrm{dBm}$ for Demux-awg and Demux-fbg in the SMF and HNLPCF fibers, respectively. From table 2 and table 3 it can be seen that for both Demux-awg and Demux-fbg systems in both fibers, the gain values are in a variation factor of approximately $-7 \mathrm{~dB}$, which was to be expected, since the length of the fibers is inversely proportional to the gain, and this is related to the noise present during the transmission that increases according to the increase in the length of the fiber.

The gain is the relationship between the output signal and the input power signal, so it can be easily seen that there is no significant gain variation with increasing power, the gain in the channels is approximately constant, figure 7 (OTHMAN et al., 2012). In addition, the output power has the same behavior as the input power, tables 2 and 3 . The output power values of Demux-AWG for SMF are very close to the output power of 
Demux-FBG, this shows us that Demux-FBG has a good performance, as well as DemuxAWG regarding the guarantee in maintaining the amplitudes of the channels at the exit, since Demux-awg is already well established.

Figure 6 - 16 channel power spectra, a) fiber input (SMF or HNL-PCF) b) SMF output and c) HNL-PCF output.

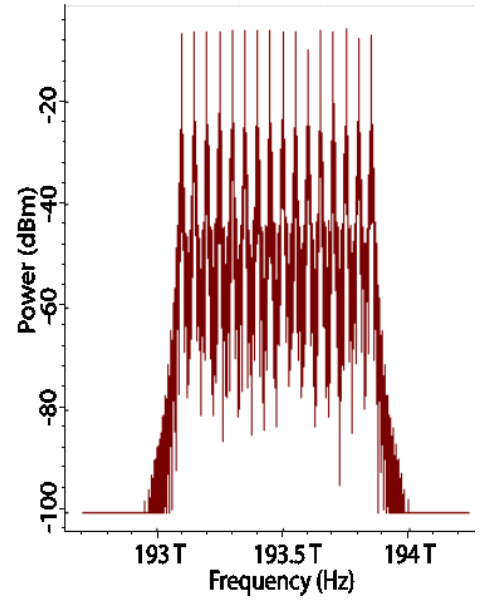

a)

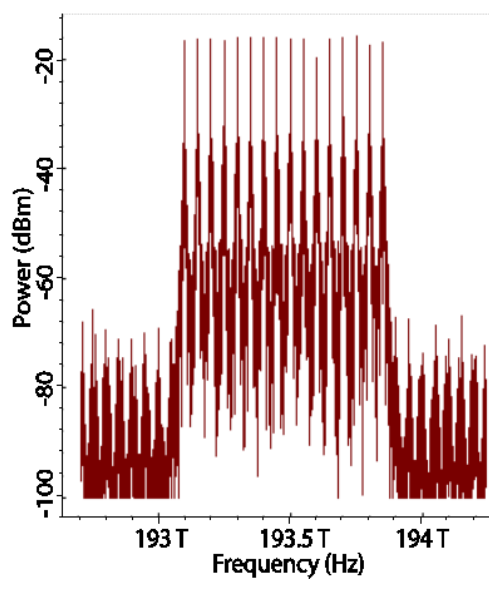

b)

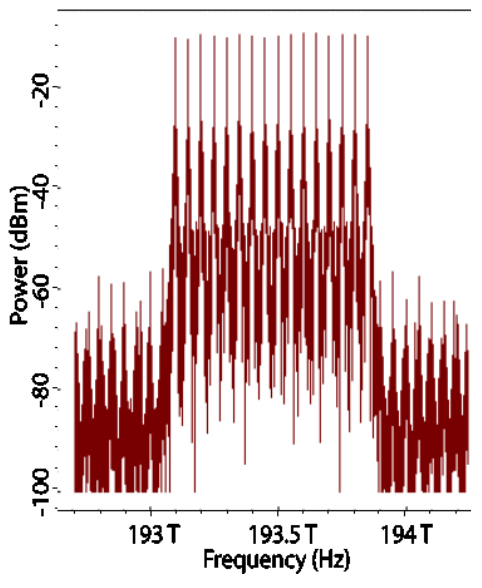

c)

Fonte: Oliveira et al. (2022).

Figure 7 - Graph of gain versus input power for demultiplexers.

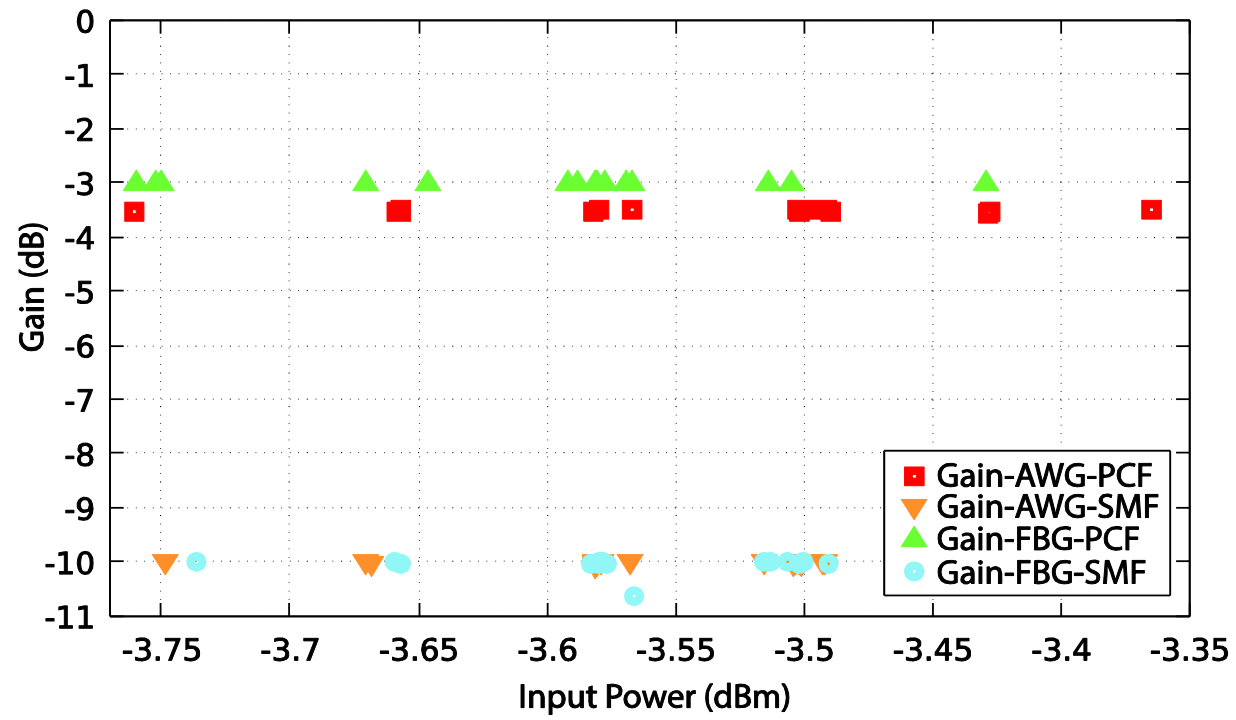

Fonte: Oliveira et al. (2022). 
It was also found that the BER values are very close, figure 8, this way it is understood that the type of grating used in Demux-fbg had parameters configured satisfactorily or that the grating was suitable for the type of fiber, which has parameters which aim to minimize dispersion, as a significant variation was observed compared to the results for the HNL-PCF fiber, figure 9. The simulations were carried out at a rate of $12 \mathrm{Gbit} / \mathrm{s}$ for a fixed insertion loss of $(0.5 \mathrm{~dB})$, thus, the effect of the variation in fiber length in relation to the signal quality can be seen in figures 8 and 9 .

Figura 8 - BER as a function of the input power of the demultiplexer awg for the HNL-PCF and SMF fiber lengths.

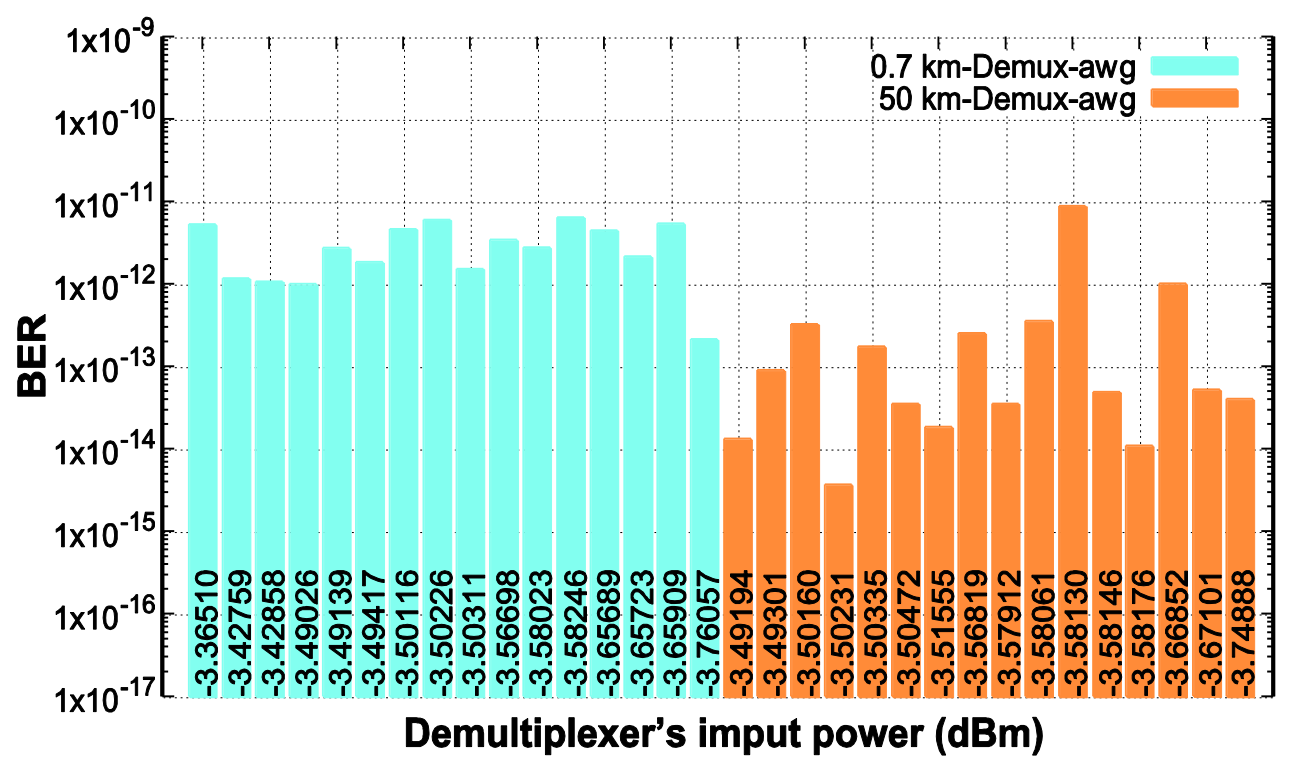

Fonte: Oliveira et al. (2022).

For the lengths of the fibers we maintained a BER less than $10^{-9}$, so if we increase the lengths of the fibers it will be necessary to amplify and compensate the dispersion to minimize these effects and the appearance of strongly non-linear effects. It is also observed that the $Q$ factor provided by Demux-awg for both fibers is very close, showing that regardless of the type of fiber, demultiplexing was well suited for the parameters of non-linearity and dispersion of HNL-PCF.

The $Q$ factor provided by Demux-fbg for both fibers is quite different, the values of Demux-fbg for the HNL-PCF fiber are more than twice the values for the Demux-fbg of the SMF fiber, this shows us that the parameters of grating had a better match with the parameters of the fiber HNL-PCF, since the factor $Q$ does not change considerably, as for 
example, between the channels of $193.55 \mathrm{THz}$ to $193.75 \mathrm{THz}$, where they are in an average value of 19.7460 , table 3 and figure $10 \mathrm{~b}$ and $10 \mathrm{c}$ highlighted in yellow.

Figure 9. BER versus the input power of the demultiplexer fbg for the lengths of the HNL-PCF and SMF fibers.

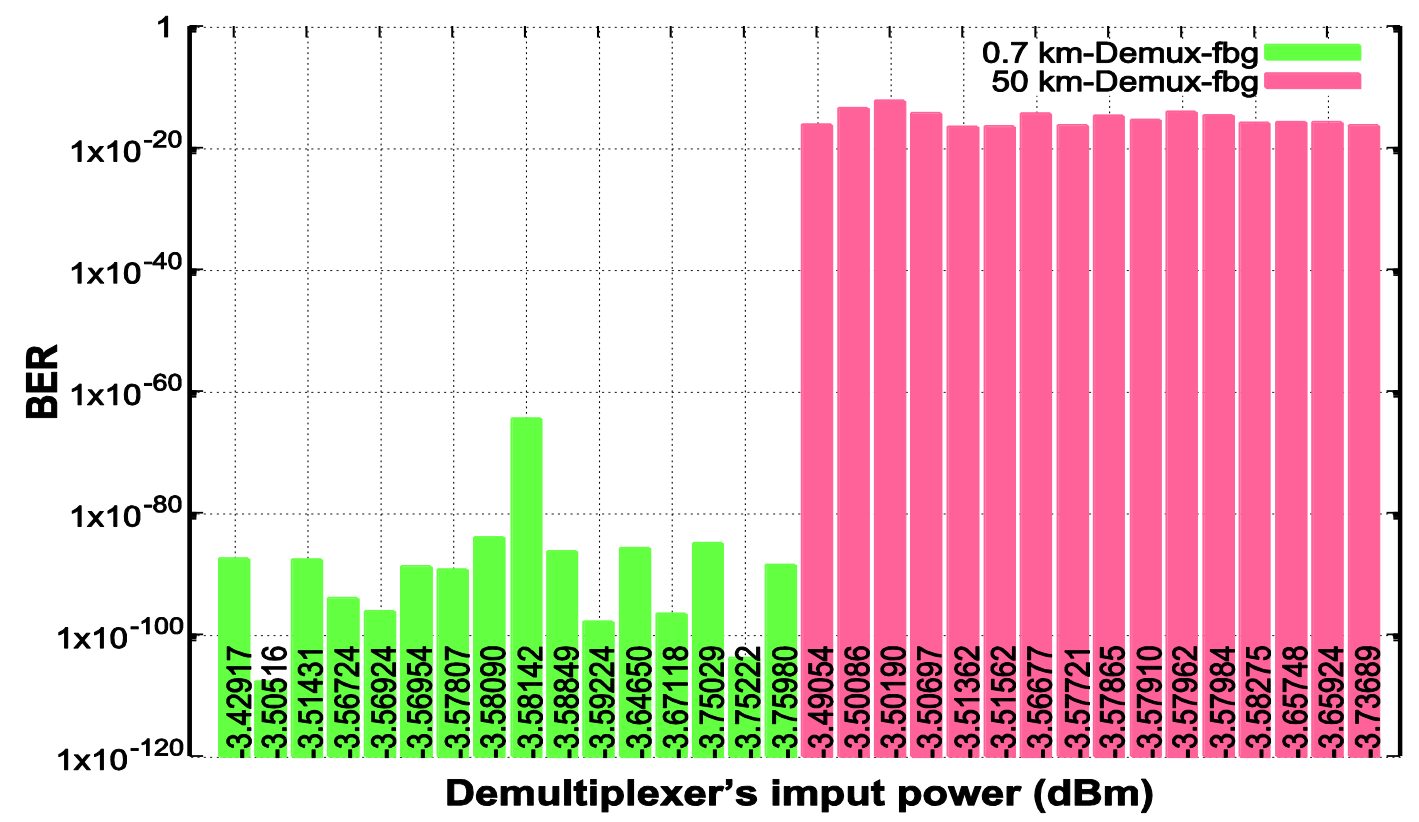

Fonte: Oliveira et al. (2022).

The $Q$ factor of the Demux-awg for the HNL-PCF fiber had a performance very similar to the Demux-awg for the SMF fiber, since we found very approximate values, in which the first channel for both fibers presents a difference of approximately 0.30, therefore, it is understood that the demultiplexer awg was quite efficient in both fibers, figure 10a highlighted in green. The $Q$ factor of Demux-fbg for the HNL-PCF fiber performed better than the Demux-fbg for the SMF fiber, since we verified very different values, where the first channel for both fibers, presents a difference of approximately 9.27, we believe that the settings of the grating parameters were a determining factor in the selection and response of the wavelengths, in addition to the length of the HNL-PCF being sufficient to reduce the nonlinear and dispersive effects during signal propagation, figure 10a highlighted in yellow (DIGGE, 2014).

The $Q$ factor data for both Demuxs showed that for the $50 \mathrm{GHz}$ DWDM system at a rate of $12 \mathrm{Gbit} / \mathrm{s}$ it was quite satisfactory, even though it is a transmission system in which the spacing between channels is very small and the relatively high transmission rate, which can be equated to some results from, in which the authors used two systems 
with dense and ultra-dense spacing, but on the other hand the transmission rate was 2.5 Gbit/s and which showed results well equivalent $Q$ factor for these data with the biggest difference for Demux-fbg. The BER for the Demux-awg on the HNL-PCF fiber has a value of BER $=1.07084 \times 10^{-012}$ in the first channel, and the Demux-awg for the SMF fiber also has a value of $\mathrm{BER}=8.88777 \times 10^{-012}$ for the first channel, comparing the results, we verified that there was a free and stable connection when thinking about more modern transmission systems and information presented in this work according to current literature (YADAV et al., 2015; PROAKIS and SALEHI, 2001).

The BER for Demux-fbg on the HNL-PCF fiber has a value of BER $=2.33519 \times$ $10^{-108}$ in the fifth channel, and the Demux-fbg for SMF fiber also has a value of BER = $7.80135 \times 10^{-017}$ for the fifth channel, observing the results, we verified that there was a stable connection about ninety orders of magnitude, this can be verified in the eye diagrams of the Demux-fbg channel $193.30 \mathrm{THz}$ for the SMF fiber and the Demux-fbg channel $193.30 \mathrm{THz}$ for the HNL-PCF fiber, where it appears more unfocused and not very high (open), fifth channel of figure 10a marked in red (BENAMEUR et al., 2012).

These results are relatively superior to those presented by (MISHRA et al., 2016), where they perform a comparative analysis of the performance of an optical fiber system with or without the use of FBG, containing transmission rates ranging from 5 to $20 \mathrm{Gbit} / \mathrm{s}$ and fiber lengths SMF optics over a range of 10 to $50 \mathrm{~km}$. For the use of FBG, optical fiber length of $50 \mathrm{~km}$ and a transmission rate of $12 \mathrm{Gbit} / \mathrm{s}$, the $Q$ factor has a value of approximately 6.500 and BER with a value close to $10^{-12}$, which shows a relatively low eye opening. Our results, as can be seen in table 3 highlighted in pink, show a $Q$ factor with an average of 8.012 and BER of the order of $10^{-16}$ for the same transmission rate and with good eye opening and little unfocused. 
Figure 10. Demux-awg and Demux-fbg eye diagrams for both fibers in a) 1 st to 6 th channels, b) 7 th to 12 th channels and c) 13 th to 16 th channels.

SMF
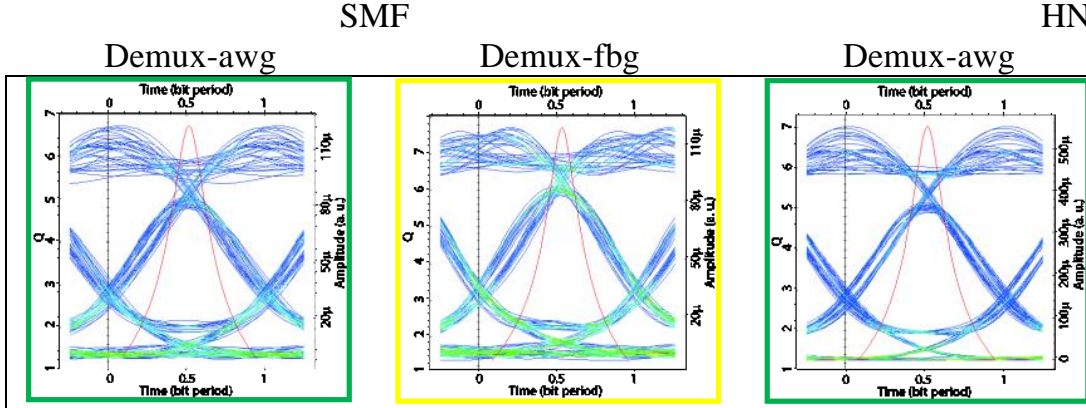

HNL-PCF
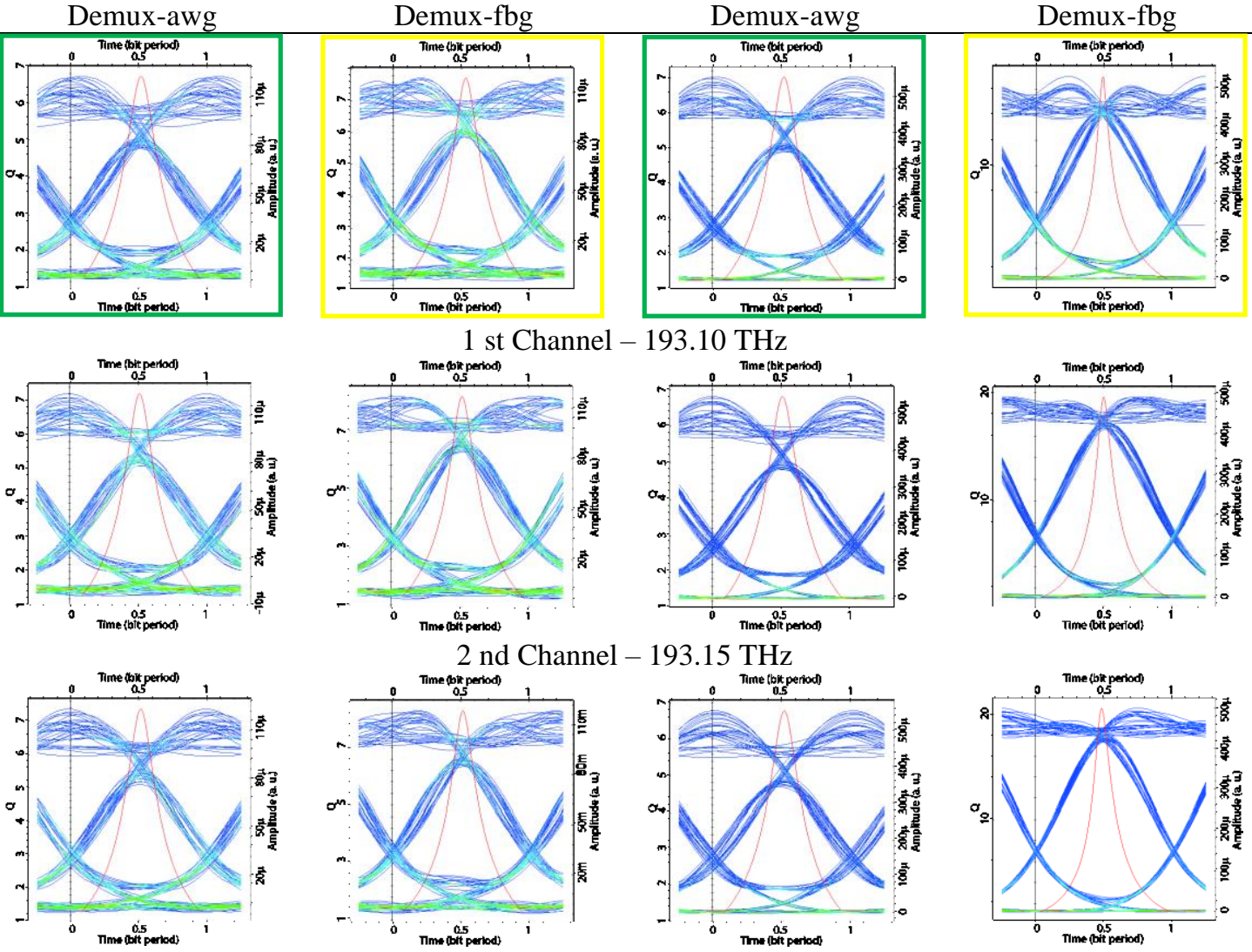

2 nd Channel $-193.15 \mathrm{THz}$
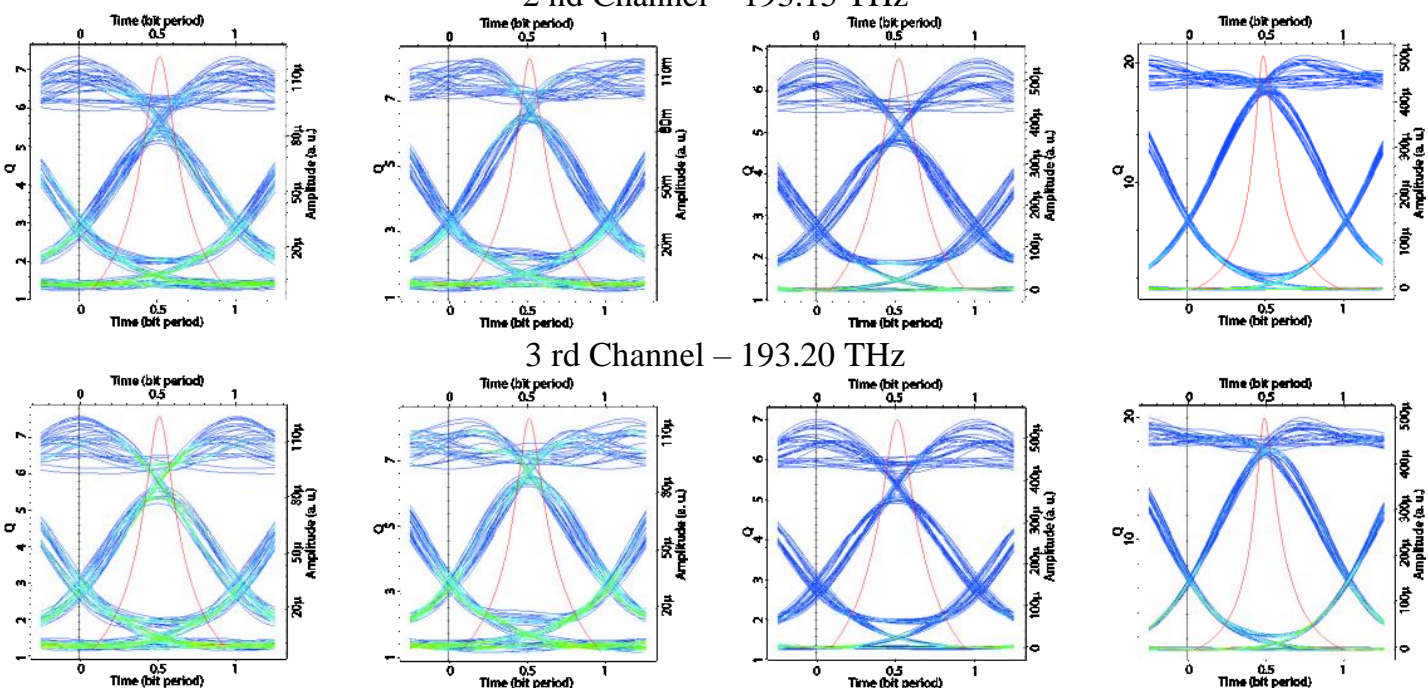

3 rd Channel - $193.20 \mathrm{THz}$
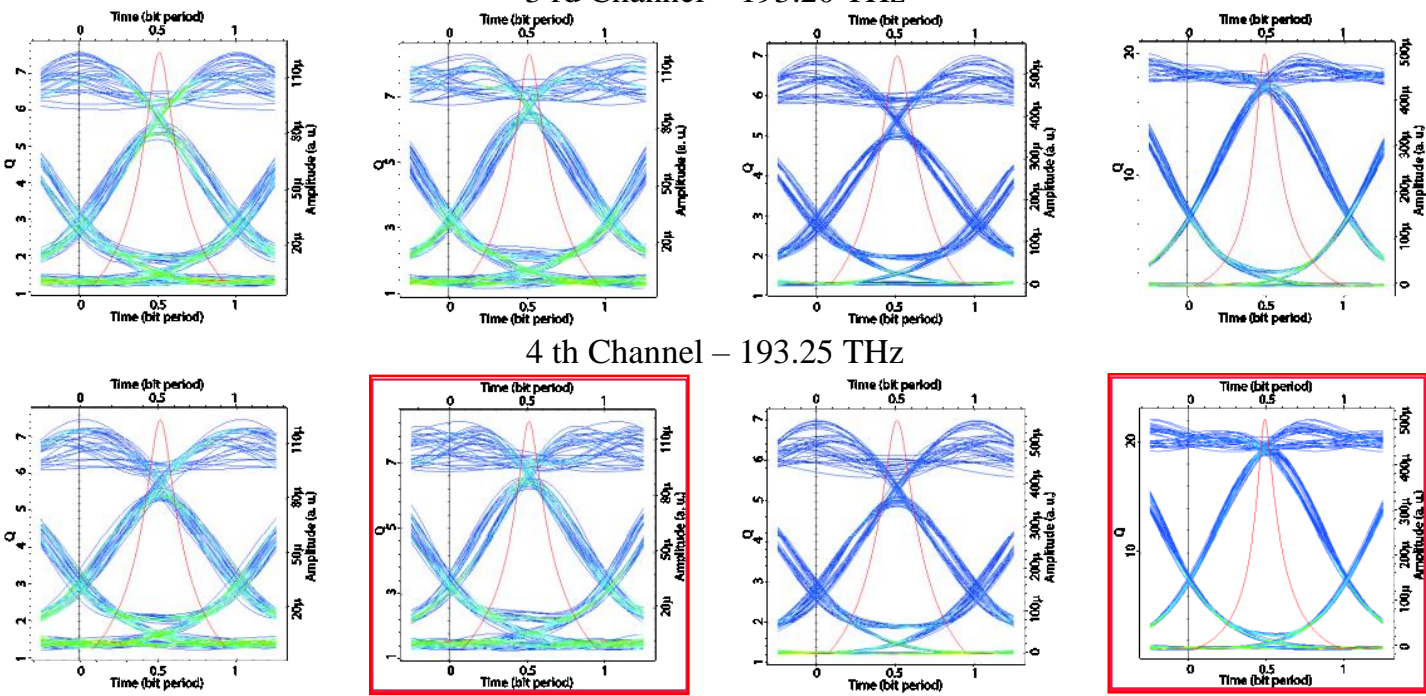

4 th Channel - $193.25 \mathrm{THz}$
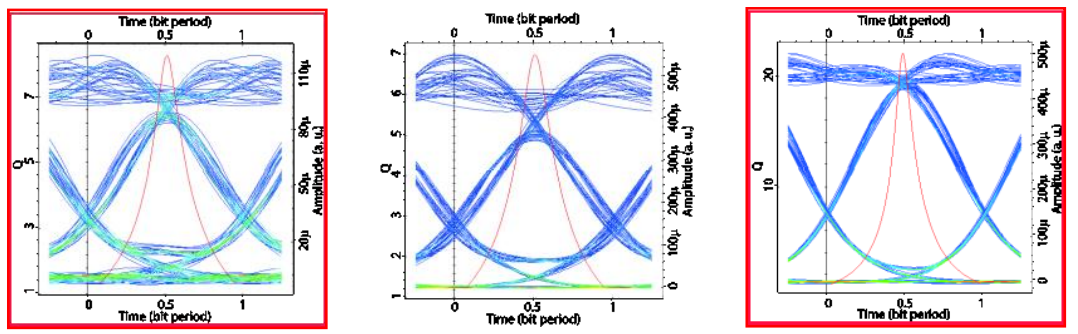

5 th Channel $-193.30 \mathrm{THz}$
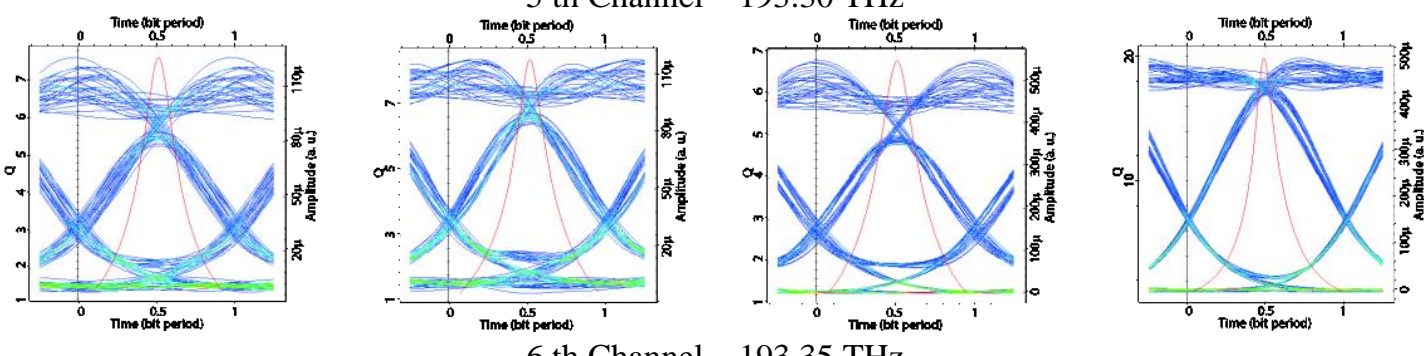

6 th Channel $-193.35 \mathrm{THz}$ 


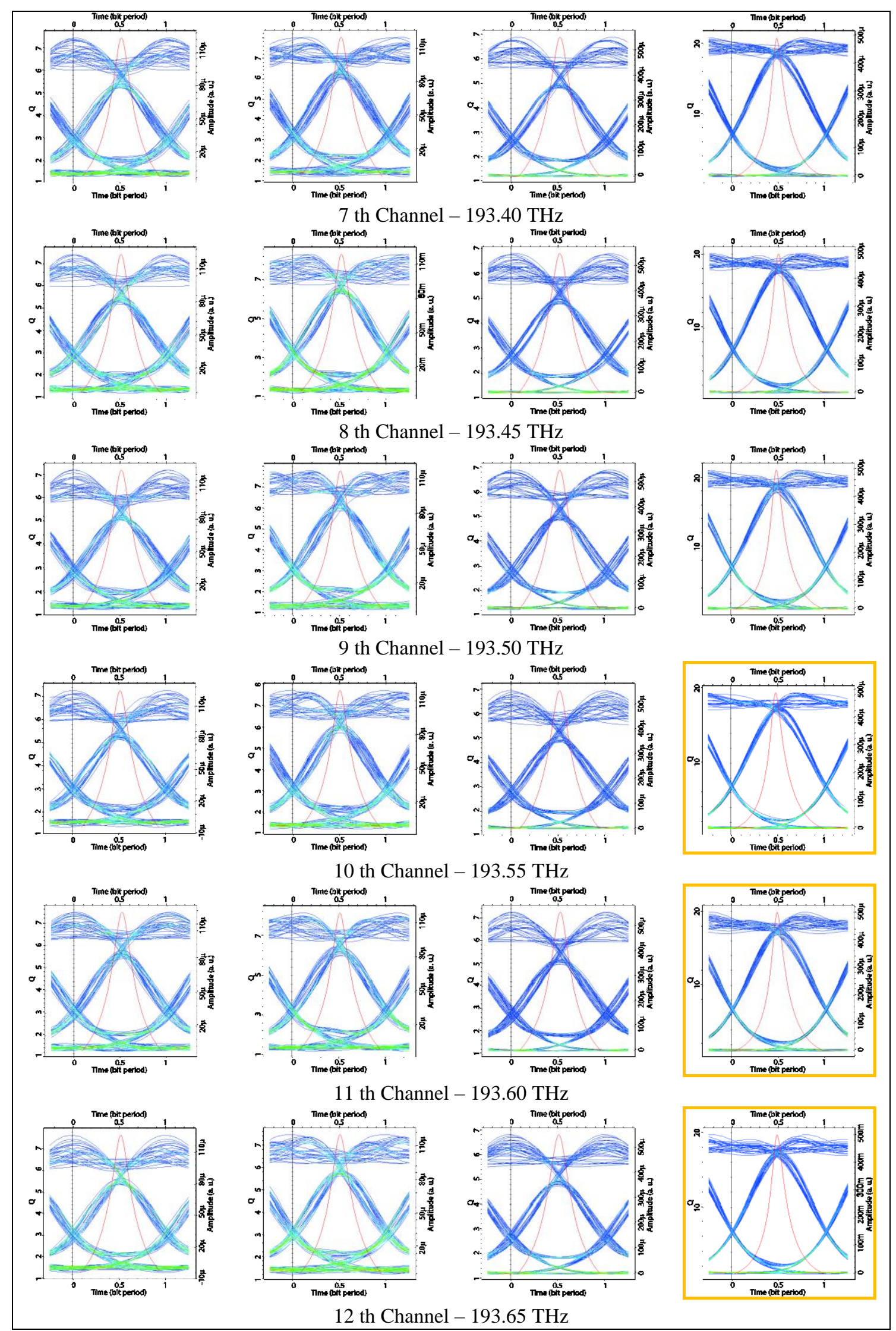

b) 


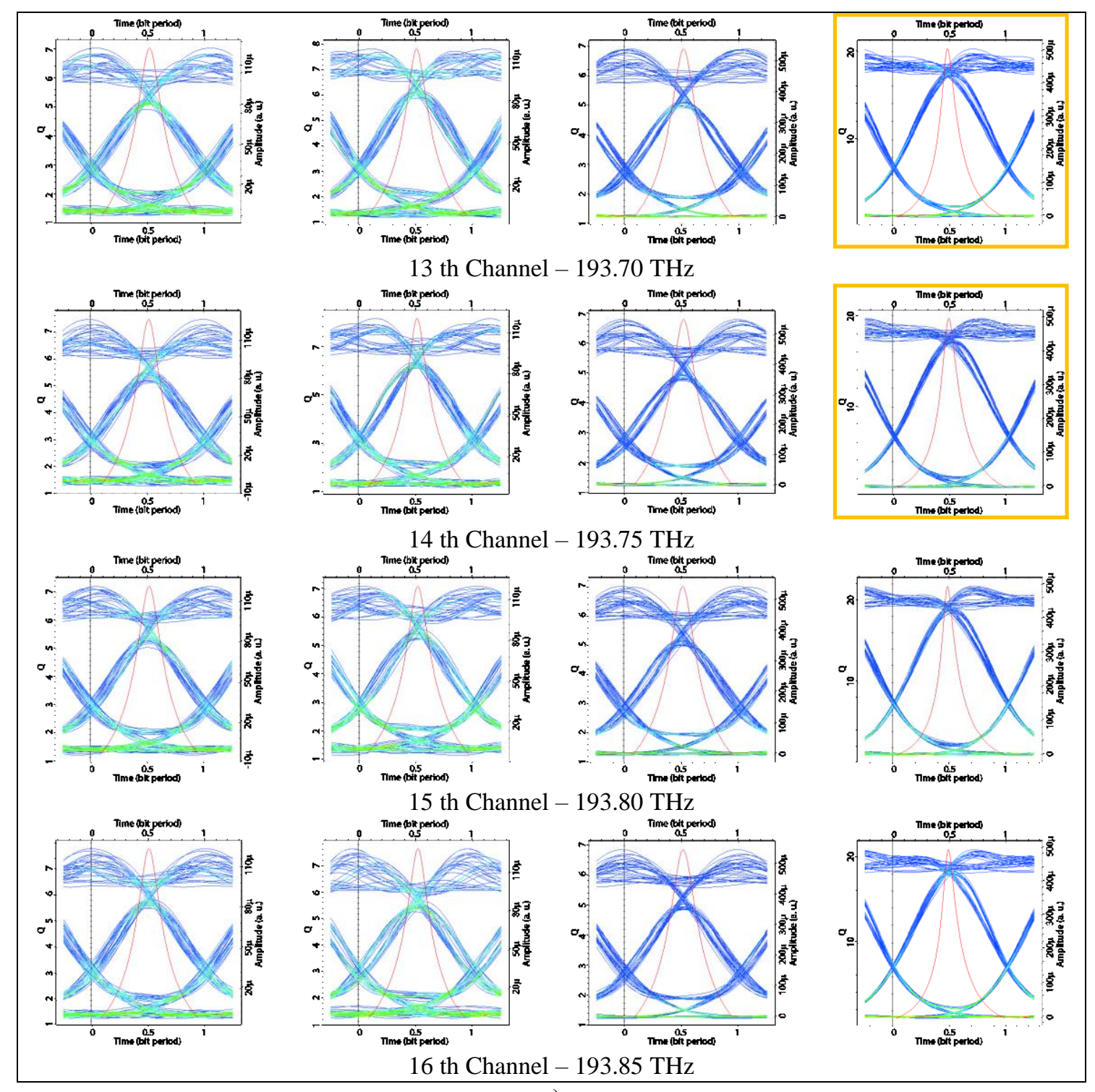

c)

Fonte: Oliveira et al. (2022).

The Demux-fbg eye diagram for the SMF fiber shows that the dispersion led to the widening of the pulse mixed with noise, which resulted in a slightly degraded signal (stressed eye) with an eye height of the order of 0.101 , figures 10a, 10b and 10c. In Mishra et al., (2016) we see results in which the height of the eye is on the order of 0.891 , so we conclude that our data show good results when compared to other simulations aimed at analyzing the performance of FBGs in WDM systems available in the literature. It is important to note that we did not perform a comparison on the two devices in relation to each other, as they are different devices, and because they are different they should be 
compared under the same conditions, as for example compared at the same rate of suppression in the lateral mode, but it would differ of the objective of the work.

\section{CONCLUSION}

The performance analysis of Demux-awg and Demux-fbg for SMF and HNL-PCF fibers was performed. At a rate of $12 \mathrm{Gbit} / \mathrm{s}$, it was observed that Demux-fbg in terms of factor $Q$ and Min. BER for the HNL-PCF fiber had better performance and stability in the free data transmission than Demux-fbg for the SMF fiber, we believe that the adjustment in the grating parameters could lead to much more interesting results for the SMF fiber. From another perspective, the Demux-awg performed well for both types of fibers, the values of factor $Q$ and Min. BER are the proof that there were no difficulties in demultiplexing the signals even in the case of a highly non-linear fiber type, such as the HNL-PCF used in the simulations. Through the simulations it was significantly possible to demonstrate the demultiplexing of the optical signal in a special type of highly nonlinear fiber, using waveguide grating and large Bragg fibers in such a way that it offered yet another possibility of optical link demultiplexing with the use of HNL-PCF fibers, in addition to having verified yet another possibility of using FBGs in cascade with circulators, passive devices, to reduce the complexity and the final cost of the project. It is easy to see that the results are innovative and bring demultiplexing with the use of FBGs with circulators in a special type of fiber, the HNL-PCF fibers, however, we know that experimental tests to validate the proposal would be fundamental, which at the moment it is something impractical due to the restrictions imposed by the health agencies in facing COVID-19, when universities and research centers are closed.

\section{REFERÊNCIAS}

AGRAWAL, G. P. Fiber-optic communication systems. John Wiley \& Sons, 2012.

ALI, A. H.; KADHIM, S. A.; KAZR, K. A.; LATEEF, A. T. Simulation and performance analysis of a fiber communication system based on FBG as dispersion compensator. Int J New Technol Res, 4, p. 62-66, 2018.

BENAMEUR, Sarah; AUPETIT-BERTHELEMOT, Christelle; KANDOUCI, Malika. Impact Of Optical Demultiplexers Based On Fiber Bragg Gratings On DWDM transmission system. In: First International Conference on Electrical Engineering and Control Applications ICEECA'2012. 2012. 
BENAMEUR, S.; KANDOUCI, M.; AUPETIT-BERTHELEMOT, C.; JOTI, A. Dense Wavelength Division (De) Multiplexers Based on Fiber Bragg Gratings. Sensors \& Transducers, 27, n. 5, p. 62, 2014.

BHUSARI SHRADDHA, N.; DESHMUKH VIKAS, U.; JAGDALE SHANTANU, S. Analysis of SPM, XPM, and FWM in fiber optic comunication using optiSystem.

IJSTE-International Journal of Science Technology \& Engineering, 2, n. 07, 2016.

CONNOLLY, E.; KASZUBOWSKA-ANANDARAJAH, A.; BARRY, L. P.; DUNNE, J. et al. Cross-channel interference due to wavelength switching events in wavelength packed switched WDM networks. Optics communications, 267, n. 1, p. 88-91, 2006.

COSTA, U. W. d. C. Análise da influência do monitoramento OTDR em WDM-PON: um estudo baseado em simulação. Dissertação (mestrado) - Programa de Pós-

Graduação em Engenharia Elétrica, Universidade Federal do Pará. Belém. 2013.

DE SOUSA, F. B.; DE OLIVEIRA, J. E.; DE SOUSA, F. M.; COSTA, M. B. C. et al. Michelson interferometer system with acoustic optic filter and fiber Bragg grating for reduction of four-wave mixing. Scientia Plena, 15, n. 7, 2019.

DE SOUSA, F. B.; DE SOUSA, F. M.; DE OLIVEIRA, J. E.; PASCHOAL, W. et al. Numerical analysis of the performance of a Mach-Zehnder interferometer based on acousto-optic filter for signal regeneration. Optical and Quantum Electronics, 52, n. 5, p. 1-12, 2020.

DIGGE, J.; RINDHE, B.; NARAYANKHEDKAR, S. Photonic crystal based arrayed waveguide grating demultiplexer for optical network. Int. J. Eng. Sci. Innov. Technol., 3, p. 358-368, 2014.

DOCKNEY, M. L.; JAMES, S. W.; TATAM, R. P. Fibre Bragg gratings fabricated using a wavelength tuneable laser source and a phase mask based interferometer.

Measurement science and technology, 7, n. 4, p. 445, 1996.

DONG, Z.; LI, X.; YU, J.; CAO, Z. et al. 8 x 9.95-Gb/s Ultra-Dense WDM-PON on a 12.5-GHz Grid With Digital Pre-Equalization. IEEE Photonics Technology Letters, 25, n. 2, p. 194-197, 2012.

HILL, K. O.; FUJII, Y.; JOHNSON, D. C.; KAWASAKI, B. S. Photosensitivity in optical fiber waveguides: Application to reflection filter fabrication. Applied physics letters, 32, n. 10, p. 647-649, 1978.

HOXHA, J. et al. FBG-and AWG-based AO-OFDM demultiplexing. In: 2015 International Conference on Photonics in Switching (PS). IEEE, p. 82-84, 2015.

KEISER, Gerd. Optical Fiber Communications. Mcgraw Hill. Fourth Edition, 2008.

MISHRA, R.; SHUKLA, N.; DWIVEDI, C. A Comparative Performance Analysis of Optical Fiber System with FBG Compensated SMF for High Data Rate. Imperial Journal of Interdisciplinary Research, 2, n. 7, 2016.

OTHMAN, M.; ISMAIL, M.; SULAIMAN, H.; MISRAN, M. et al. An analysis of 10 Gbits/s optical transmission system using fiber Bragg grating (FBG). IOSR Journal of Engineering (IOSRJEN), 2, n. 07, p. 55-61, 2012. 
PROAKIS, John G.; SALEHI, Masoud. Digital communications. New York:

McGraw-hill, 2001.

SOUSA, Fabio B. de et al. All-optical 3R regeneration based on an acousto optical filter with Q-Factor improvement. Journal of Computational and Theoretical Nanoscience, v. 15, n. 6-7, p. 1871-1875, 2018.

YADAV, A.; JAISWAL, A.; NITIN, N. Comparative Analysis of AWG Demultiplexer and Chirped FBG based Demultiplexer in WDM PON Network. International Journal of Computer Applications, 121, n. 11, 2015.

Recebido em: 01/02/2022

Aprovado em: 01/03/2022

Publicado em: 03/03/2022 